D0I: 10.12957/demetra.2018.30496

\title{
Vitamina D e Selênio na Tireoidite de Hashimoto: espectadores ou jogadores?
}

Vitamin D and Selenium in Hashimoto's Thyroiditis: bystanders or players?

Luana Rezende Rocha Vilela'

Daniela Canuto Fernandes'

' Pontifícia Universidade Católica de Goiás, Escola de Ciências Sociais e da Saúde, Curso de Nutrição. Goiânia, GO, Brasil.

Correspondência / Correspondence Luana Rezende Rocha Vilela E-mail: luanavilela.nut@gmail.com

\section{Resumo}

Objetivo: investigar as evidências científicas da relação da vitamina D e do selênio sobre os níveis séricos de hormônios tireoidianos, anticorpo TPOAb e da atividade enzimática, bem como o efeito da suplementação. Metodologia: a pesquisa foi realizada utilizando-se as bases de dados PubMed, Scopus e Web of Science, e os limites, tipo de estudo (artigos originais e metanálises), idioma (inglês, espanhol e português) e o tempo de publicação (últimos dez anos). Resultados: indivíduos com tireoidite de Hashimoto possuem maior prevalência de deficiência de vitamina $\mathrm{D}(\mathrm{n}=11)$, a qual pode contribuir para a proliferação de anticorpos, porém sem relação com os hormônios tiroxina e triiodotironina. Quanto ao selênio, a suplementação contribuiu para redução de anticorpos $(\mathrm{n}=5)$ e melhora do perfil hormonal $(\mathrm{n}=6)$. Conclusão: indivíduos com tireoidite de Hashimoto cursam com baixos níveis séricos de vitamina $\mathrm{D}$, e a suplementação tanto de calcitriol quanto de selênio parece ser eficaz para a redução de anticorpos e melhora do perfil hormonal, porém ainda não há evidências científicas convincentes que sustentem essa conduta.

Palavras-chave: Doença de Hashimoto. Vitamina D. Selênio.

\section{Abstract}

Objective: To investigate the scientific evidence of how vitamin D and selenium are related to serum levels of thyroid hormones, antiTPOAb antibodies and enzymatic activity, as well as the effect of supplementation. Methodology: The study was carried out by using 
PubMed, Scopus and Web of Science databases, limited according to type of study (original articles and meta-analyses), language (English, Spanish and Portuguese) and publication time (last ten years). Results: Individuals with Hashimoto's thyroiditis have a higher prevalence of vitamin D deficiency $(n=11)$, which may contribute to the proliferation of antibodies, but it is unrelated to the hormones thyroxine and triiodothyronine. As for selenium, supplementation contributed to the reduction of antibodies $(\mathrm{n}=5)$ and improvement of the hormonal profile $(\mathrm{n}=6)$. Conclusion: Individuals with Hashimoto's thyroiditis have low serum levels of vitamin D and the supplementation of both calcitriol and selenium seem to be effective for the reduction of antibodies and improvement of the hormonal profile, but so far there is no convincing scientific evidence to support such practice.

Keywords: Hashimoto Disease. Vitamin D. Selenium.

\section{Introdução}

A tireoide é uma glândula do sistema endócrino que se origina do epitélio faríngeo, estando localizada na região anterior e caudal da cartilagem laríngea. Essa glândula é responsável pela secreção dos hormônios tiroxina (T4) e triiodotironina (T3), e tem sua função regulada por mecanismos supratireoideanos e intratireoideanos. ${ }^{1}$

A regulação supratireoideana é realizada pelo hormônio estimulador da tireoide (TSH), secretado pelas células basófilas da adeno-hipófise. O TSH é responsável por estimular a hipertrofia e a hiperplasia da tireoide e a síntese de hormônios tireoidianos, bem como regular seu metabolismo e participar da síntese de ácidos nucleicos e proteínas. A regulação intratireoidiana é realizada pela fração de iodo orgânico glandular, essencial para a síntese de T3 e T4. ${ }^{1}$

A vitamina D também se destaca por suas propriedades imunomoduladoras sobre macrófagos, linfócitos T e B e células dendríticas, por causa da existência do receptor de vitamina D (VDR) no núcleo celular, e da enzima 1-alfa-hidroxilase na superfície das mesmas. Essa vitamina é capaz de inibir a ativação de células T, a produção de células T helper 1 (Thl), células dendríticas, interferon gama (INF- $\gamma$ ) e interleucina 2 (IL-2), assim como inibir a proliferação e induzir a apoptose de células $\mathrm{B}$, podendo conduzir a um efeito protetor nas doenças autoimunes. ${ }^{2,3}$

Na deficiência de calcitriol, há maior expressão de antígeno leucocitário humano (HLA-DR) de classe II nos tireócitos, proliferação de linfócitos, maior secreção de citocinas inflamatórias, 
maturação de células dendríticas e maior expressão do complexo principal de histocompatibilidade de classe II (MHC-II). Consequentemente, há maior proliferação de células B e maior produção de anticorpos, contribuindo para o dano celular.,

Além do iodo, o selênio é outro mineral importante para o metabolismo e síntese de hormônios tireoidianos. É constituinte das principais selenoproteínas expressas pela glândula, como a glutationa peroxidase (GPX), a tireoredoxina redutase (TR) e as iodotirosinas desiodinases (DIO), responsáveis pelos processos de eliminação de peróxidos de hidrogênio $\left(\mathrm{H}_{2} \mathrm{O}_{2}\right)$ e desiodinação. ${ }^{6}$

Na deficiência de selênio, há redução da atividade de GPX e TR, responsáveis por catalisarem a redução de peróxidos e hidroperóxidos de hidrogênio, produzidos durante a síntese de hormônios T3 e T4, além da redução da atividade de DIO responsáveis pelos processos de desiodinação. Sendo assim, na deficiência desse mineral, pode ocorrer aumento das espécies reativas de oxigênio, levando a danos oxidativos na estrutura folicular da glândula, o que ativa o sistema imune e o processo fibrótico, e conversão ineficiente de hormônios tireoidianos. ${ }^{6}$

As doenças autoimunes da tireoide representam a patologia endócrina mais prevalente na população, ${ }^{7}$ sendo a tireoidite de Hashimoto caracterizada por taxas elevadas de anticorpos antitireoglobulina (TG) e tireoperoxidase (TPOAb), e por infiltração de células T e B, que contribuem para deterioração glandular e exacerbação de sintomas. A reação autoimune é desencadeada quando os tireócitos expressam o HLA-DR de classe II, processo induzido pela produção de células Thl e citocinas inflamatórias, sobretudo IFN-gama, que podem ser inibidos pelo calcitriol. ${ }^{3,8}$

Nessa perspectiva, e tendo em vista a ação imunomoduladora da vitamina D e a função do selênio no metabolismo tireoidiano, o objetivo desta pesquisa foi investigar as evidências científicas da relação desses nutrientes com os níveis de hormônios, anticorpo TPOAb e atividade enzimática, bem como o efeito da suplementação na tireoidite de Hashimoto.

\section{Metodologia}

Seleção das bases de pesquisa e estratégias de busca

A presente revisão foi realizada nas bases de dados PubMed, Scopus e Web of Science, nos últimos dez anos (2007 a 2017), utilizando-se as estratégias de busca mostradas na figura 1. 


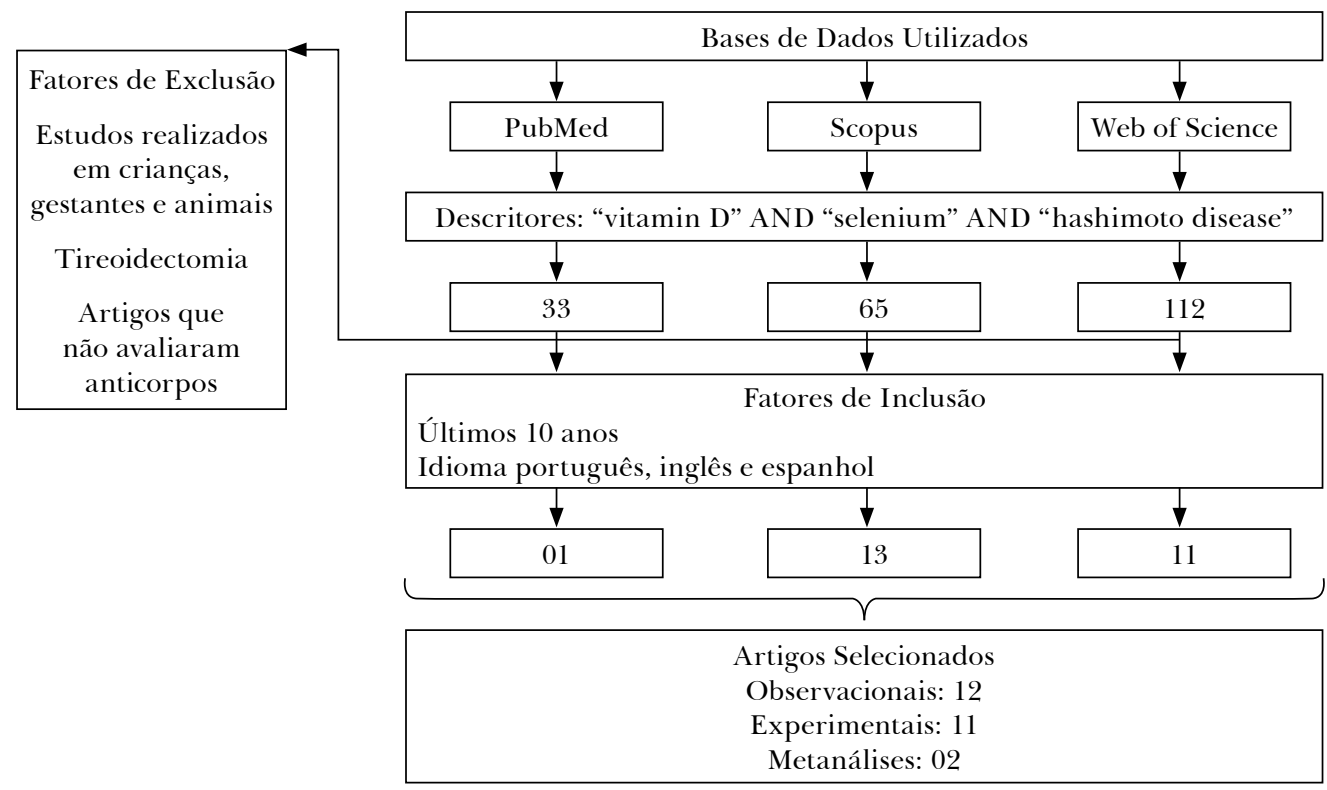

Figura 1. Representação esquemática das estratégias de pesquisa bibliográfica

Além dos artigos obtidos nas bases, as referências de trabalhos previamente selecionados, bem como publicações técnico-científicas, foram incluídas nesta revisão, a fim de ampliar a pesquisa sobre o tema.

\section{Critérios de inclusão e de exclusão}

Foram incluídos artigos com desenho observacional, experimental e metanálise, com metodologia e protocolos de intervenção bem delineados. Além disso, incluíram-se apenas artigos que avaliaram o anticorpo TPOAb como critério diagnóstico da tireoidite de Hashimoto. Excluíramse as pesquisas realizadas com crianças, gestantes e indivíduos submetidos a tireoidectomia, assim como em modelos animais.

\section{Análise crítica}

Após a seleção dos artigos, estes foram lidos na íntegra, e as informações principais foram tabuladas nos quadros 1 e 2. A análise crítica foi realizada pelos dois autores, avaliando-se os 
objetivos dos artigos, tipo de estudo, coerência metodológica, protocolo de intervenção, resultados e conclusão. Utilizou-se a checklist do método PRISMA como parâmetro para a análise crítica. ${ }^{9}$

\section{Resultados}

Foram selecionados 25 artigos, conforme a figura 1. Os estudos foram realizados em diversas regiões: Grécia, Sul da Itália, Tessalônica, Roma, Amsterdã, Turquia, Coreia do Sul, Irã, Istambul, China e Polônia.

\section{Niveis séricos de vitamina $D$}

Onze estudos analisaram a prevalência da deficiência da vitamina D em indivíduos com tireoidite de Hashimoto, sendo que todos encontraram níveis significativamente menores nesses indivíduos, quando comparados ao grupo controle., ${ }^{2,4,5,10-17}$

\section{Vitamina D e anticorpos TPOAb}

Ma et al. ${ }^{11}$ e Mansournia et al. ${ }^{12}$ observaram relação negativa entre os níveis séricos de vitamina D e os anticorpos. No entanto, Giovinazzo et al., ${ }^{5}$ Shin et al., ${ }^{13}$ Unal et al. ${ }^{14}$ e Bozkurt et al. ${ }^{4}$ encontraram uma relação positiva $(r=0,17$ a $r=0,669)$, estando em concordância com Mazokopakis et al. ${ }^{18}$ e Chaudhary et al., ${ }^{19}$ que após suplementação via oral com colecalciferol, observaram redução dos níveis séricos de anticorpos TPOAb $(r=0,43)$, com concomitante aumento dos níveis de vitamina D. Cabe destacar que as doses da suplementação variaram de 1.200 a 60.000 UI.

\section{Vitamina D e hormônios tireoidianos}

Chaudhary et al. ${ }^{19}$ observaram que indivíduos com $\mathrm{TSH}<10 \mathrm{mIU} / \mathrm{L}$ obtiveram redução significativa de anticorpos TPOAb, após a suplementação com colecalciferol, fato não observado no grupo com TSH>10mIU/L. Giovinazzo et al., ${ }^{5}$ Mazokopakis et al., ${ }^{18} \mathrm{Kim}^{16}$ e Guleryuz et al. ${ }^{15}$ encontraram relação negativa entre as variáveis, contrariando os achados de Unal et al. ${ }^{14} \mathrm{e}$ Mansournia et al., ${ }^{12}$ que observaram uma relação positiva entre vitamina D e TSH $(r=0,21 ; r=$ 0,34 ; respectivamente). 


\begin{tabular}{|c|c|c|c|c|c|}
\hline & 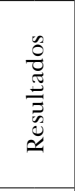 & 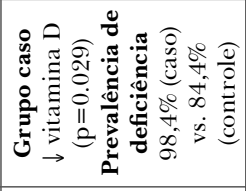 & 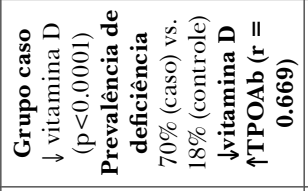 & 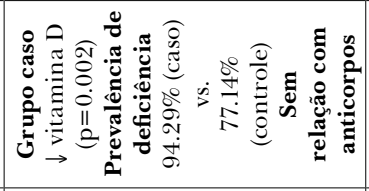 & 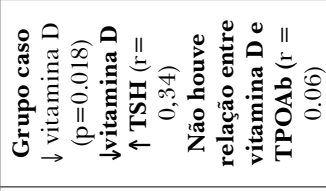 \\
\hline & 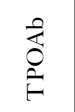 & 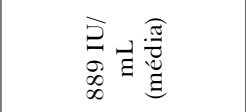 & $\begin{array}{l}\sum_{10} \\
\infty \\
\infty \\
\infty \\
0\end{array}$ & 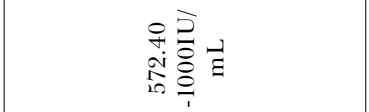 & $\vdots$ \\
\hline & $\underset{\omega}{\tilde{H}}$ & $\vdots$ & 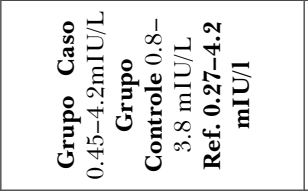 & 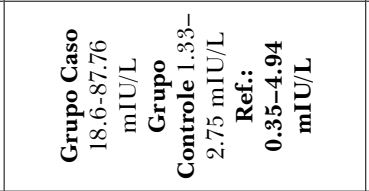 & 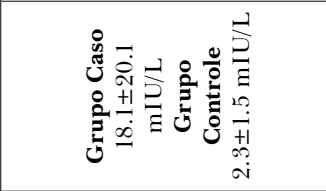 \\
\hline & $\mathbb{H}$ & ! & 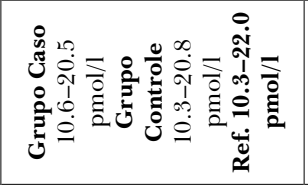 & 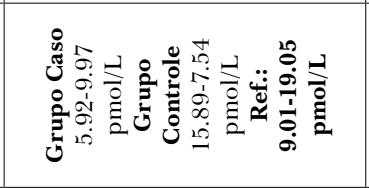 & $\vdots$ \\
\hline & $\stackrel{m}{\leftrightarrow}$ & $\vdots$ & 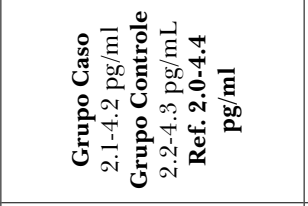 & 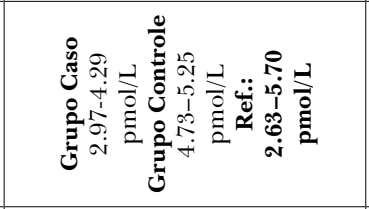 & $\vdots$ \\
\hline & 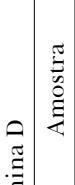 & 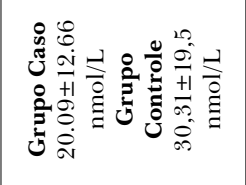 & 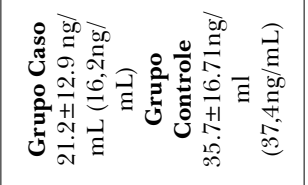 & 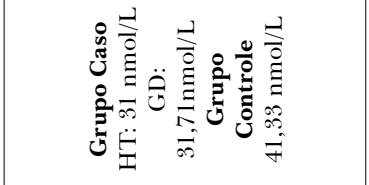 & 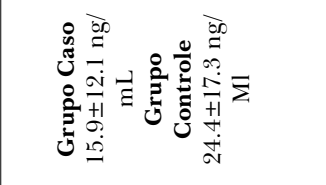 \\
\hline & 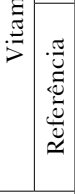 & 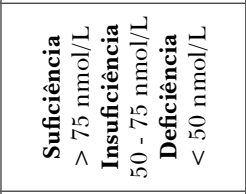 & 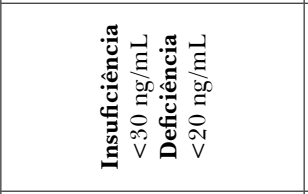 & 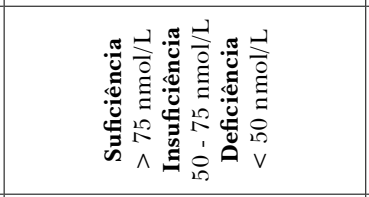 & 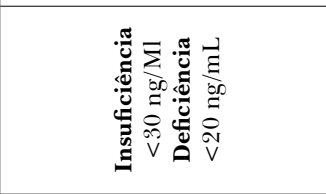 \\
\hline & 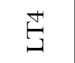 & is & z & : & $\vdots$ \\
\hline & $\begin{array}{l}\frac{\pi}{5} \\
\frac{5}{0} \\
\stackrel{g}{8}\end{array}$ & 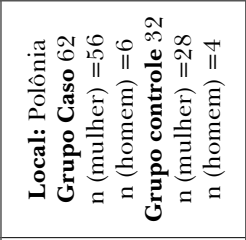 & 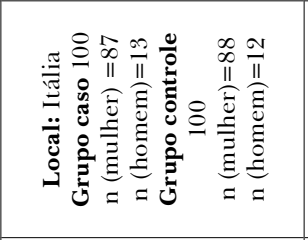 & 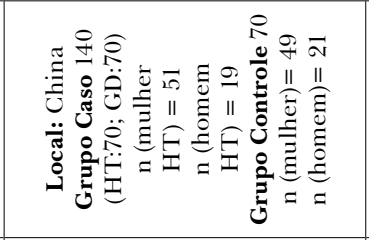 & 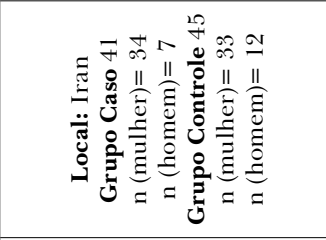 \\
\hline & 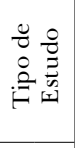 & 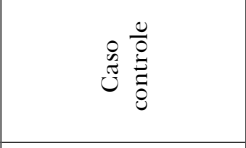 & 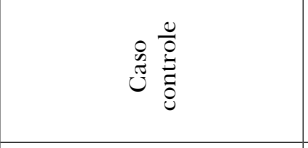 & 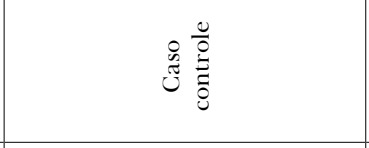 & 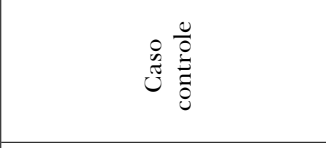 \\
\hline & $\stackrel{\vec{g}}{4}$ & 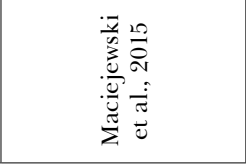 & 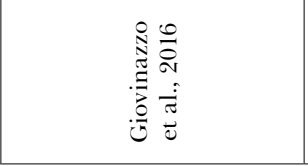 & 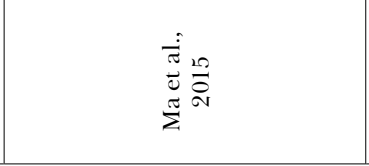 & 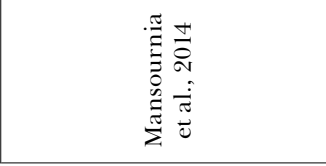 \\
\hline
\end{tabular}




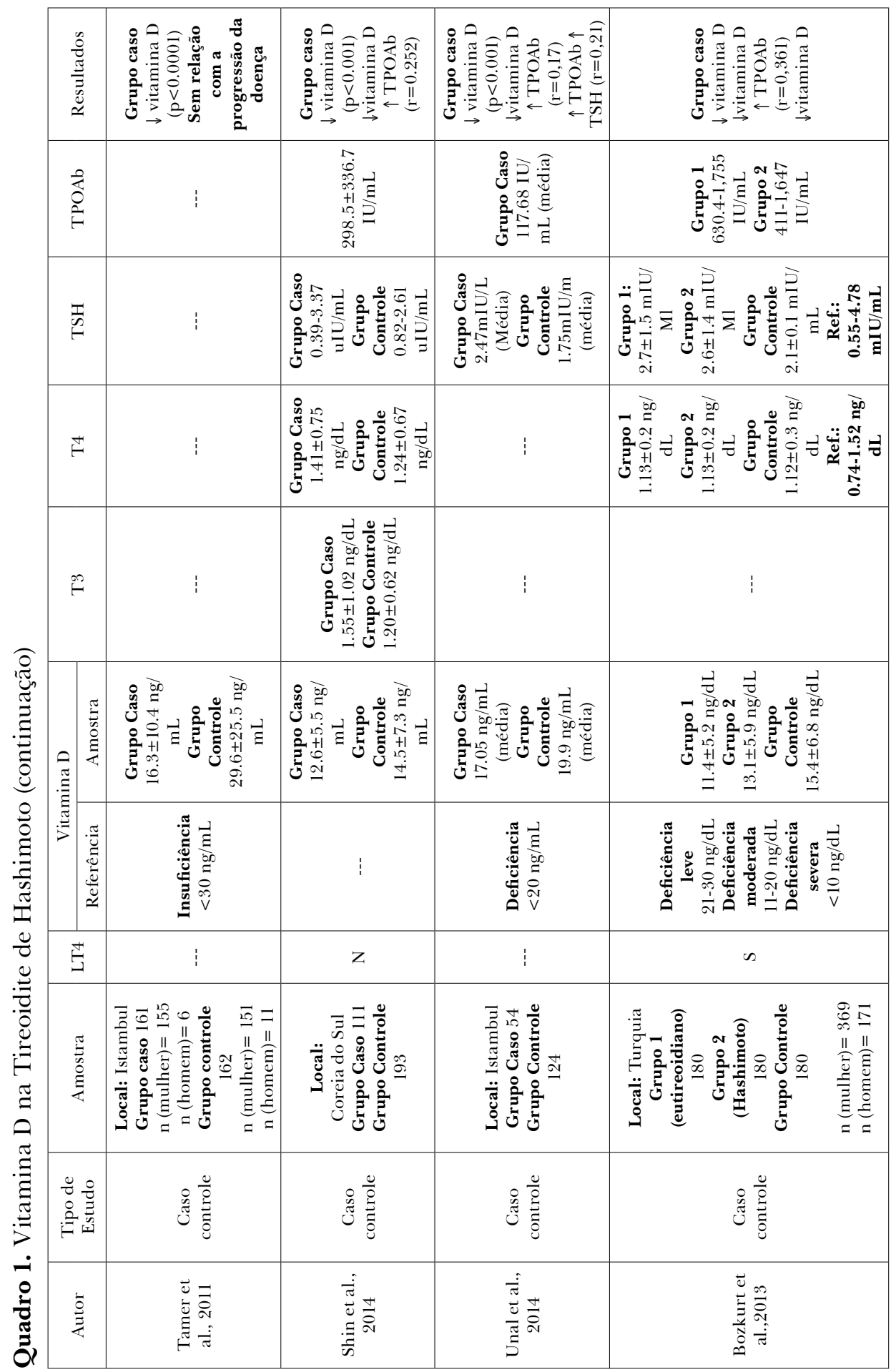




\begin{tabular}{|c|c|c|c|c|}
\hline 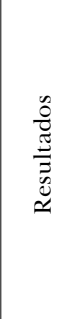 & 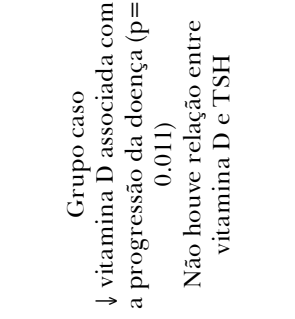 & 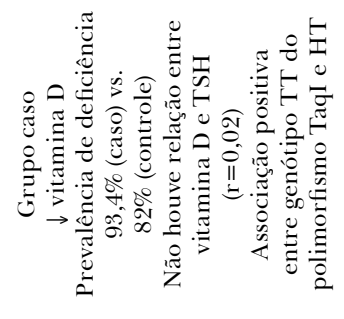 & 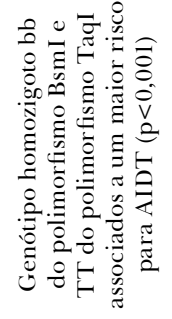 & 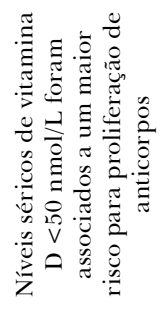 \\
\hline 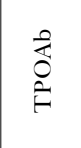 & 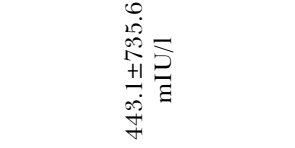 & $\vdots$ & $\vdots$ & $\vdots$ \\
\hline$\underset{\omega}{\tilde{\omega}}$ & 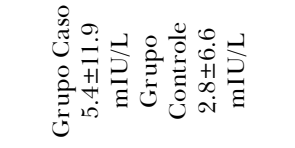 & 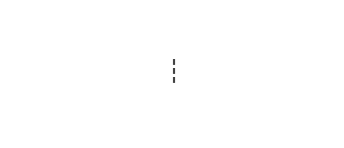 & $\vdots$ & $\vdots$ \\
\hline 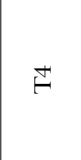 & 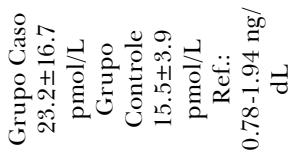 & $\vdots$ & $\vdots$ & $\vdots$ \\
\hline$\stackrel{m}{H}$ & $\vdots$ & 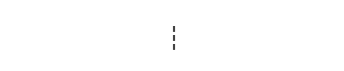 & $\vdots$ & 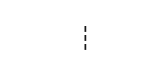 \\
\hline 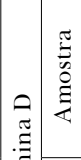 & 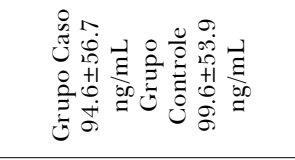 & 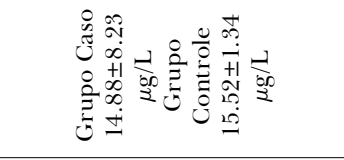 & $\vdots$ & $\vdots$ \\
\hline 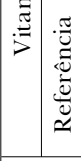 & 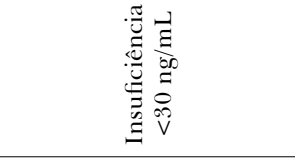 & 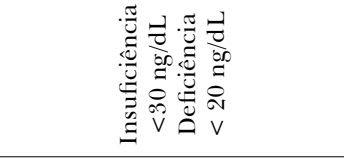 & $\vdots$ & $\vdots$ \\
\hline 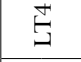 & n & $\vdots$ & $\vdots$ & $\vdots$ \\
\hline $\begin{array}{l}\frac{\pi}{5} \\
\frac{5}{8} \\
\frac{g}{4}\end{array}$ & 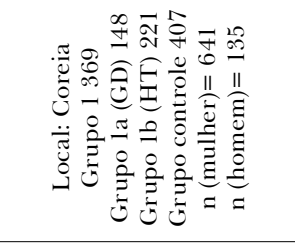 & 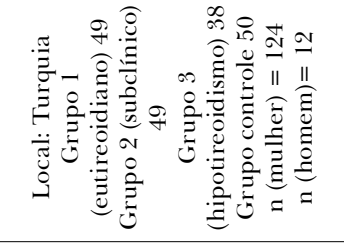 & $\vdots$ & 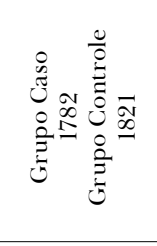 \\
\hline 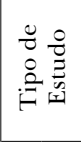 & 品 & 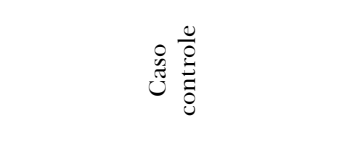 & 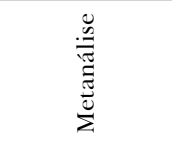 & 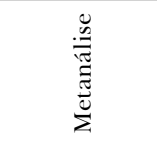 \\
\hline 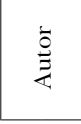 & हี่ & 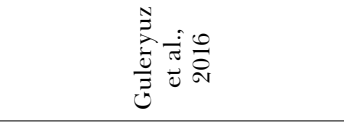 & 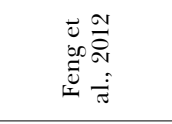 & 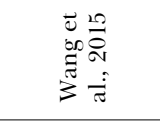 \\
\hline
\end{tabular}




\begin{tabular}{|c|c|c|c|c|c|}
\hline & 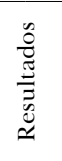 & 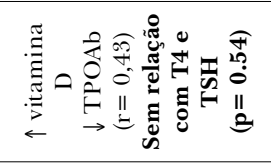 & 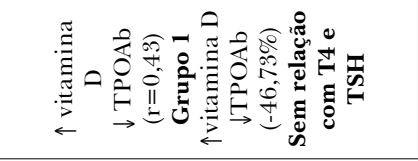 & 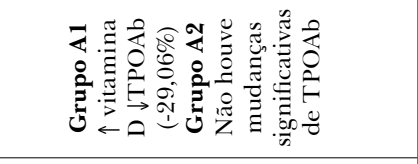 & \\
\hline & $\begin{array}{l}\stackrel{0}{0} \\
\stackrel{0}{F} \\
\hat{F}\end{array}$ & 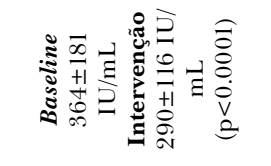 & 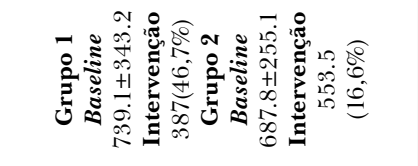 & 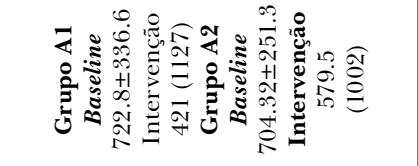 & \\
\hline & $\underset{⿱ 乛}{\tilde{n}}$ & 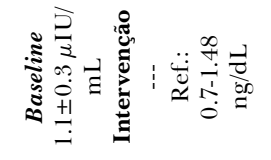 & 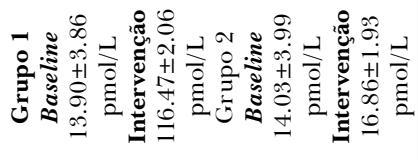 & 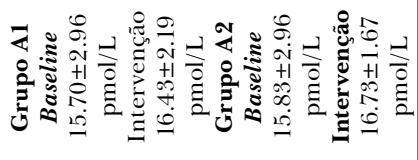 & \\
\hline & $\ddot{H}$ & $\vdots$ & $\vdots$ & $\vdots$ & \\
\hline & $\stackrel{\infty}{\leftrightarrow}$ & 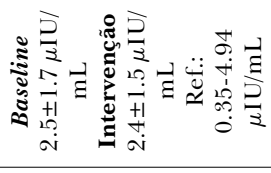 & 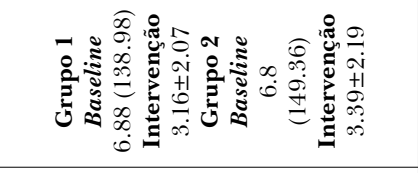 & 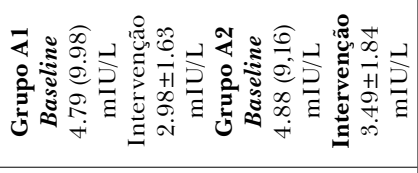 & \\
\hline & 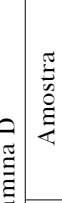 & 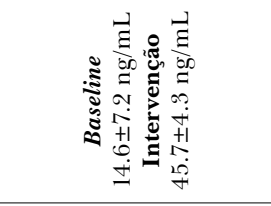 & 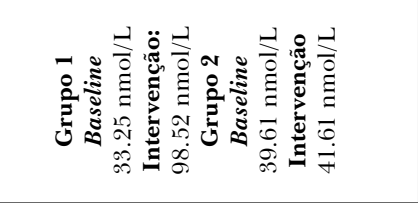 & 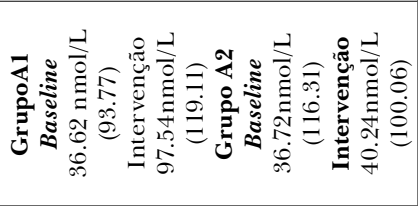 & \\
\hline & 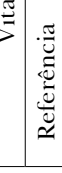 & 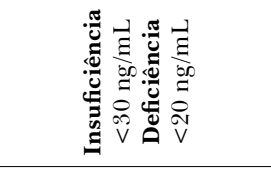 & 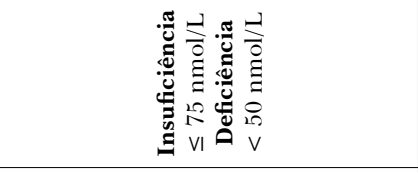 & 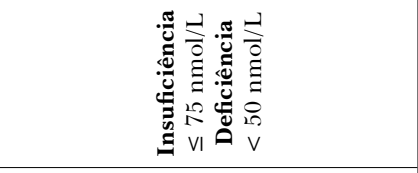 & \\
\hline & 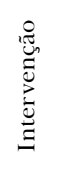 & 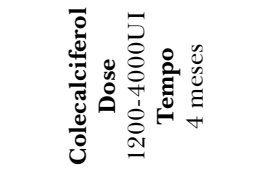 & 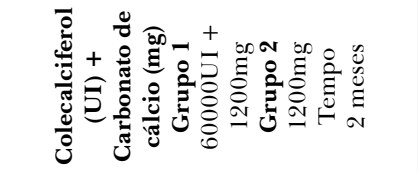 & 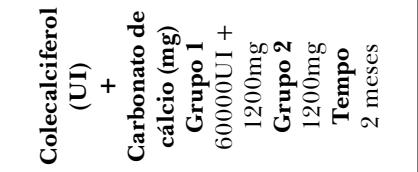 & \\
\hline & 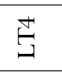 & in & in & n & \\
\hline & $\begin{array}{l}\tilde{G} \\
\text { के } \\
\stackrel{g}{\xi}\end{array}$ & 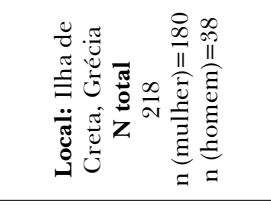 & 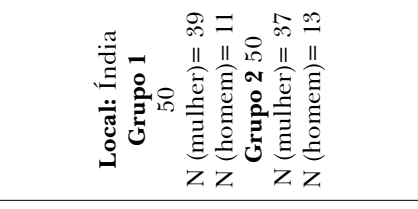 & 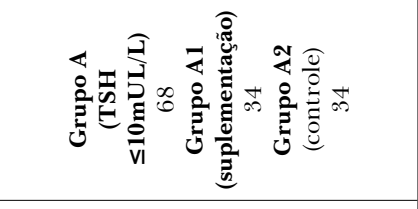 & \\
\hline & 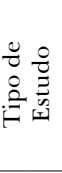 & 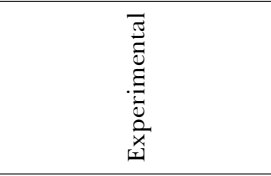 & & & \\
\hline & $\stackrel{\overline{3}}{\xi}$ & 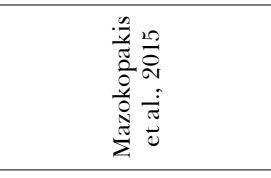 & $\Xi$ & & \\
\hline
\end{tabular}




\section{Selênio, anticorpos e hormônios tireoidianos}

Nove artigos avaliaram a relação entre a suplementação de selênio, anticorpos e hormônios TSH, T3 e T4. Seis estudos encontraram redução significativa de anticorpos após suplementação de selenito de sódio ou selenometionina..$^{20-25}$ Entretanto, as quantidades suplementadas $(80 \mu \mathrm{g} \mathrm{a} 200 \mu \mathrm{g} /$ dia), bem como a duração dos estudos (3, 6 ou 12 meses), variaram bastante. Em contrapartida, três artigos não observaram benefícios com a suplementação. ${ }^{26-28}$ Além disso, do total de estudos, quatro encontraram mudanças significativas em relação aos hormônios tireoidianos. ${ }^{21-23,26}$ 


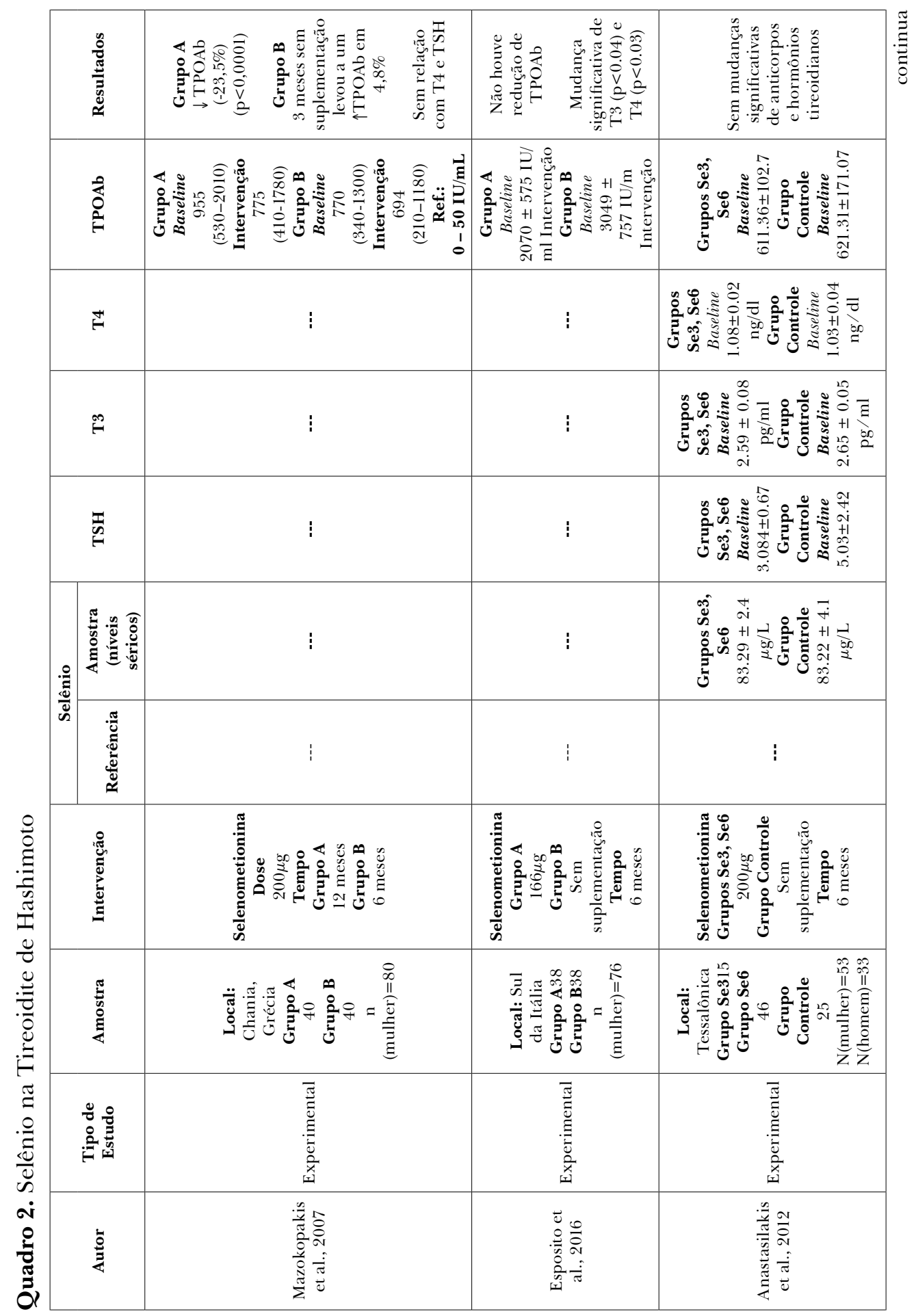




\begin{tabular}{|c|c|c|c|}
\hline & 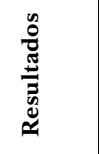 & 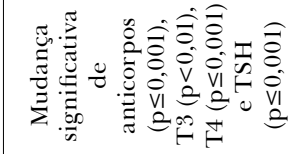 & 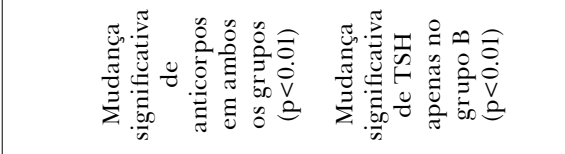 \\
\hline & 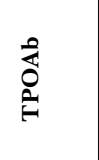 & 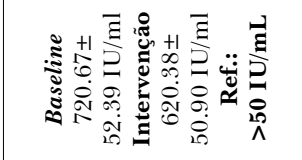 & 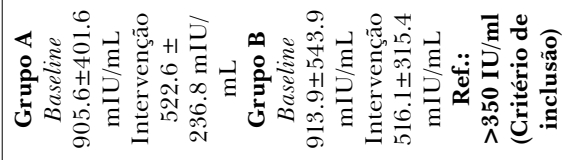 \\
\hline & $\vec{H}$ & 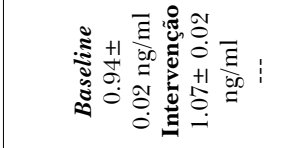 & $\vdots$ \\
\hline & $\stackrel{\infty}{\rho}$ & 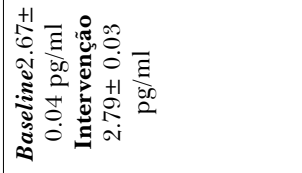 & $\vdots$ \\
\hline & $\underset{H}{T}$ & 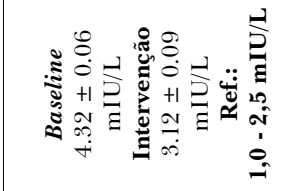 & 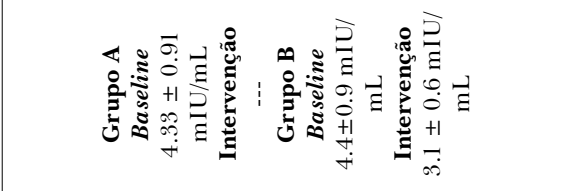 \\
\hline 赵 & 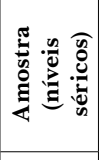 & ! & 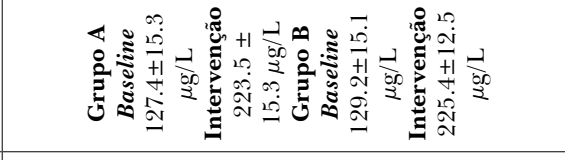 \\
\hline ळू & 莺 & $\vdots$ & $\vdots$ \\
\hline & 总 & 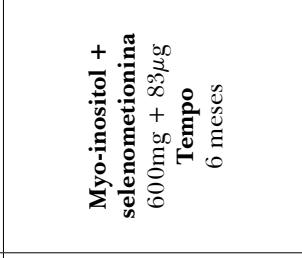 & 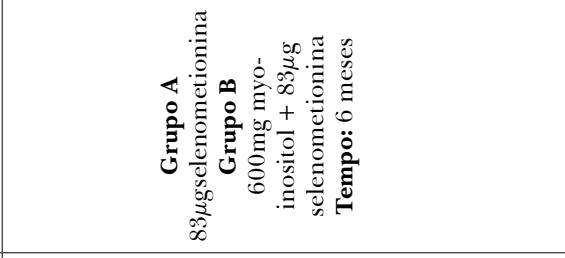 \\
\hline & $\frac{5}{5}$ & 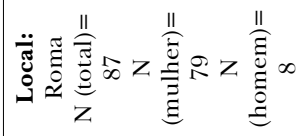 & 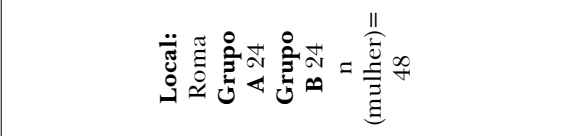 \\
\hline & 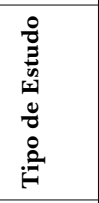 & 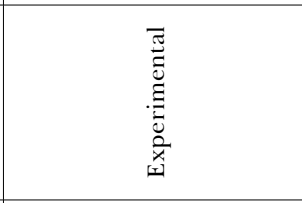 & 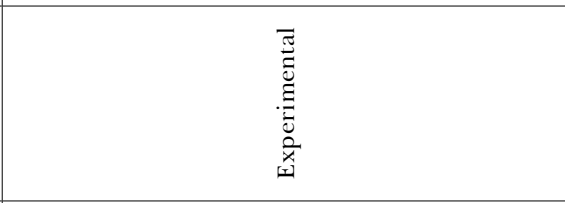 \\
\hline & 娄 & 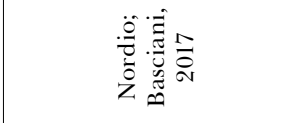 & 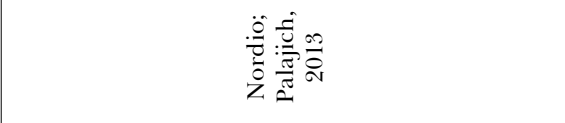 \\
\hline
\end{tabular}




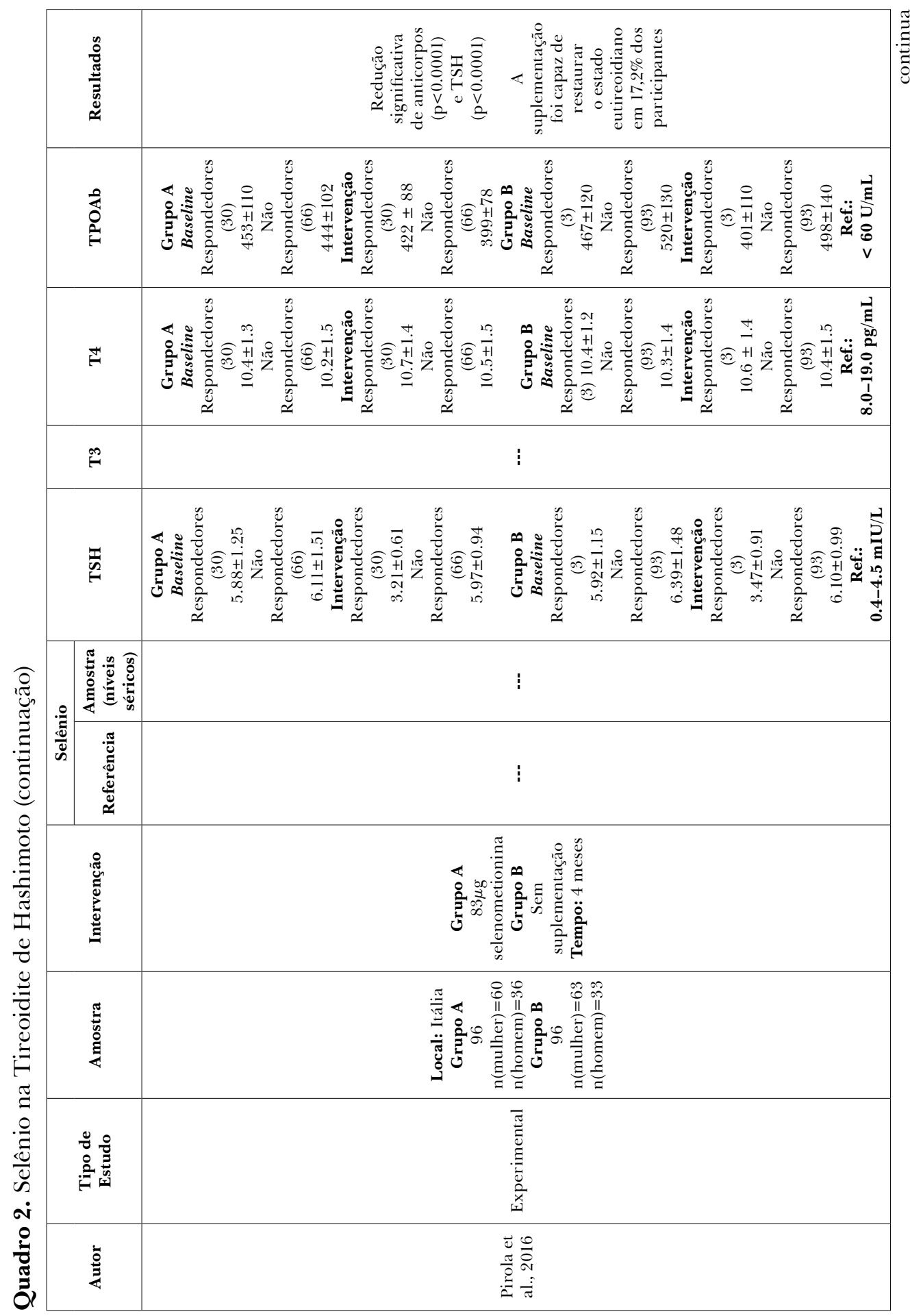




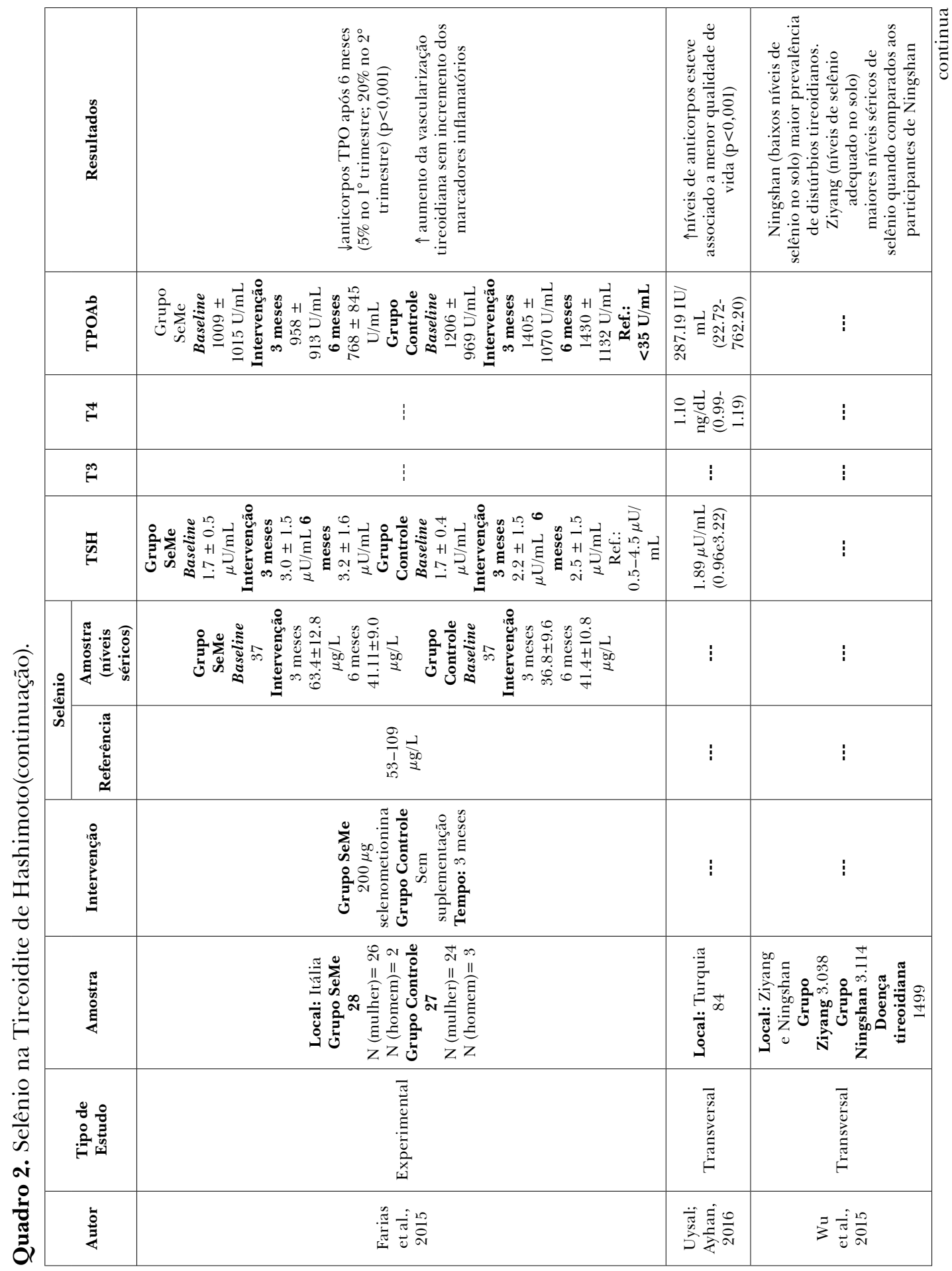




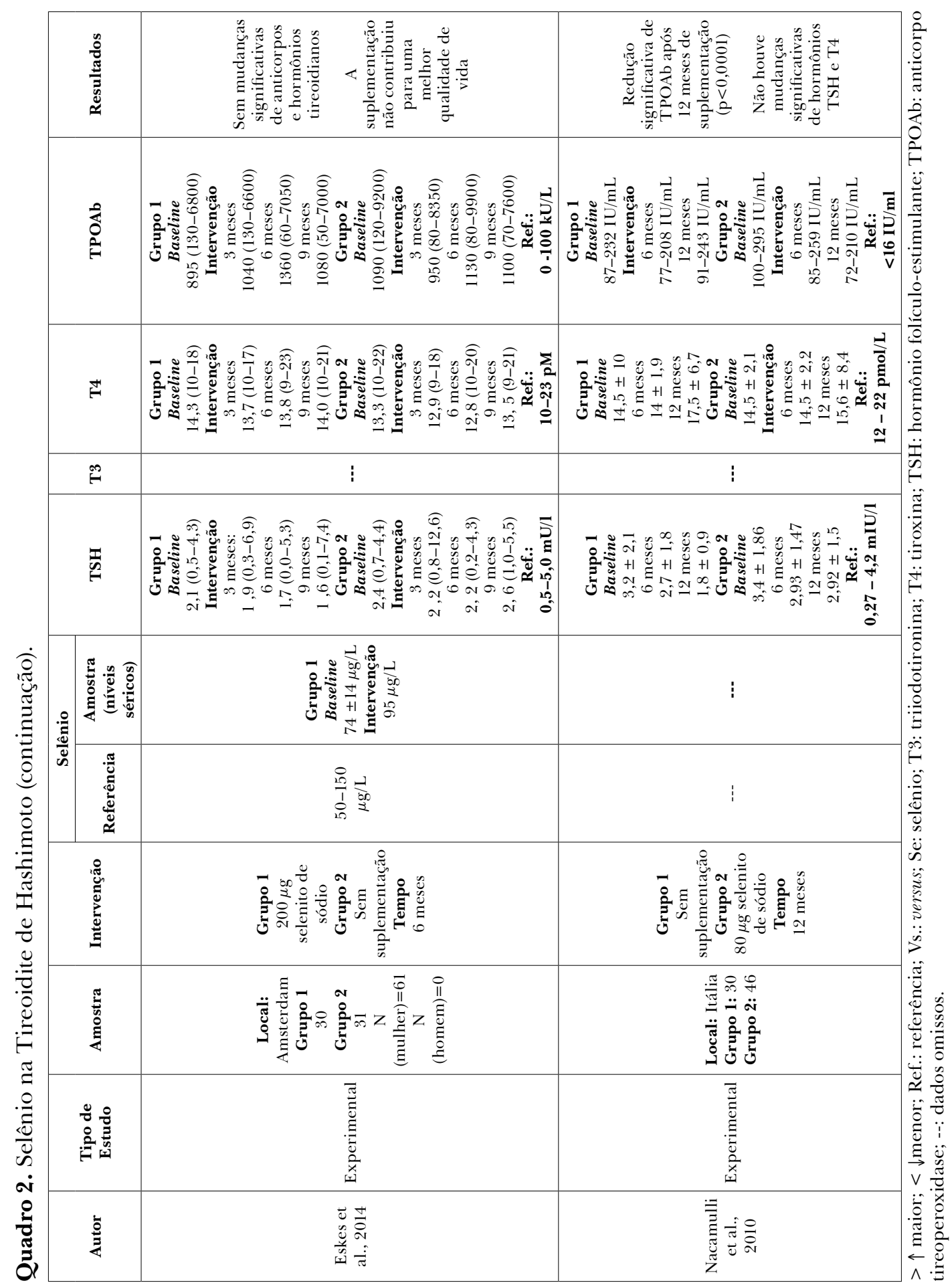




\section{Discussão}

\section{Vitamina D e Tireoidite de Hashimoto}

A prevalência da deficiência de vitamina $\mathrm{D}$ vem aumentando em todo o mundo, configurando um problema de saúde que afeta mais de um bilhão de pessoas. O calcitriol possui funções anti-inflamatória e imunomoduladora, sendo relacionado ao desenvolvimento de doenças autoimunes. ${ }^{29}$ Para análise da deficiência de vitamina D, os estudos utilizam como referência os valores adotados pela Endocrine Society Clinical Practice Guideline. ${ }^{30}$ Nesse caso, definem-se como deficiência, insuficiência e suficiência de vitamina D valores menores ou iguais a $20 \mathrm{ng} / \mathrm{mL}(50$ $\mathrm{nmol} / \mathrm{L})$; entre $21 \mathrm{ng} / \mathrm{mL}$ a $29 \mathrm{ng} / \mathrm{mL}(52,5-72,5 \mathrm{nmol} / \mathrm{L})$ e iguais ou maiores do que $30 \mathrm{ng} / \mathrm{mL}$ $(75 \mathrm{nmol} / \mathrm{L})$, respectivamente. ${ }^{30}$

Maciejewski et al. ${ }^{10}$ relataram que os níveis séricos de vitamina D foram significativamente menores e mais prevalentes em pacientes com Hashimoto em relação ao grupo controle $(98,4 \%$ vs. 84,4\%), corroborando os achados de Bozkurt et al. ${ }^{4}$ e $\mathrm{Kim}^{16}$. Esses estudos foram conduzidos em indivíduos sob terapia de reposição hormonal, a qual pode contribuir para maior depuração metabólica de calcitriol. Entretanto, aqueles realizados em indivíduos que não recebiam terapia de reposição hormonal encontraram resultados similares, como mostra o quadro 1.

Tamer et al. ${ }^{2}$ também observaram níveis séricos de vitamina D menores no grupo Hashimoto, porém sem relação com a progressão da doença. Ma et al. ${ }^{11}$ e Mansournia et al. ${ }^{12}$ relataram ainda que o aumento de $5 \mathrm{nmol} / \mathrm{L}$ nos níveis séricos de vitamina $\mathrm{D}$ foi associado a uma redução de 1,62 e 0,81 (respectivamente) do risco em desenvolver a doença.

Na deficiência de vitamina $\mathrm{D}$, há maior expressão de células Th1, maior produção de citocinas inflamatórias e maior expressão de MHC II na superfície de células dendríticas, contribuindo para maior proliferação de células B e, consequentemente, maior produção de anticorpos ${ }^{4,5}$ Giovinazzo et al., ${ }^{5}$ Shin et al., ${ }^{13}$ Unal et al. ${ }^{14}$ e Bozkurt et al. ${ }^{4}$ encontraram relação inversa entre níveis séricos de vitamina $\mathrm{D}$ e anticorpos ( $\mathrm{r}=0,17$ a r=0,669), mesmo após ajustados aos fatores de confusão (idade, IMC e gênero). Apenas dois estudos encontraram relação positiva entre vitamina D e níveis séricos de hormônios tireoidianos. ${ }^{12,14}$ Em uma metanálise, Wang et al. ${ }^{17}$ concluíram que os níveis séricos de vitamina $\mathrm{D}<50 \mathrm{nmol} / \mathrm{L}$ estão associados a maior risco de proliferação de anticorpos TPOAb.

Há que se discutir que a literatura acerca do efeito da suplementação da vitamina $\mathrm{D}$ na tireoidite de Hashimoto ainda é escassa. Mazokopakis et al., ${ }^{18}$ ao analisarem o efeito da suplementação de colecalciferol (1.200 a 4.000UI) nos níveis de anticorpos, durante quatro meses, observaram redução significativa destes $(\mathrm{r}=0,43)$. Chaudhary et al. ${ }^{19}$ também encontraram resultados semelhantes, sendo que o grupo suplementado obteve redução de 46,73\% nos níveis de anticorpos, porém a dose utilizada foi muito superior (60.000UI de colecalciferol) em menor tempo (2 meses). Os benefícios observados com a suplementação não foram dose-dependentes. 
O relação entre o hipotireoidismo de Hashimoto e polimorfismos de VDR também podem estar associados a menores níveis de vitamina D e maior suscetibilidade em desenvolver a doença, considerando que células T autorreativas podem se desenvolver na ausência de VDR funcional, conforme observado nos estudos a seguir. Guleryuz et al. ${ }^{15}$ associaram o genótipo homozigoto TT do polimorfismo TaqI, no gene VDR, a um maior risco em desenvolver a doença, enquanto que Djurovic et al. ${ }^{31}$ encontraram maior associação relacionada ao polimorfismo no VDR-FokI. Em recente metanálise, Feng et al..$^{32}$ encontraram associação significativa entre o genótipo homozigoto bb do polimorfismo BsmI e TT do polimorfismo TaqI $(\mathrm{p}<0,001)$ a um maior risco em desenvolver doenças autoimunes da tireoide, não estando relacionadas com polimorfismos ApaI e Fokl. Entretanto, Giovinazzo et al. ${ }^{5}$ não encontraram associação entre a tireoidite de Hashimoto e a variação genotípica. Os dados são conflitantes, uma vez que muitos estudos não analisam a influência direta da variação alélica na expressão de VDR, mas entre os parâmetros fisiológicos de interesse. ${ }^{31}$

Assim, não existem evidências científicas suficientes sobre a suplementação de vitamina D na tireoidite de Hashimoto. Além disso, observaram-se desenhos metodológicos muito distintos, ressaltando-se as discrepâncias na dose e na duração dos estudos.

\section{Selênio e tireoidite de Hashimoto}

A tireoide é o tecido que possui maior concentração de selênio por unidade de peso. As principais funções desse mineral na glândula estão relacionadas à atividade antioxidante e conversão de T4 em T3, ${ }^{33}$ sendo constituinte principal da selenoproteína P (SePP) e de enzimas necessárias para o metabolismo tireoidiano: GPX, TR e DIO. ${ }^{34}$

Todas as etapas da síntese de hormônios tireoidianos são catalisadas pela tireoperoxidase, a qual utiliza $\mathrm{H}_{2} \mathrm{O}_{2}$, produzido durante esse processo. Sendo assim, as espécies reativas de oxigênio (EROS) e os radicais livres são formados constantemente, participando de processos fisiológicos e patológicos. As células desenvolvem mecanismos de defesa para limitar a ação das EROS, protegendo-as de danos oxidativos. Dessa forma, a deficiência de selênio pode resultar em produção de T3 e eliminação de $\mathrm{H}_{2} \mathrm{O}_{2}$ ineficientes, além de contribuir para a iniciação do processo oxidativo, fibrose e reparação prejudicada de tecidos tireoidianos. ${ }^{35}$

Em relação ao efeito da suplementação, Mazokopakis et al., ${ }^{20}$ ao utilizarem $200 \mu \mathrm{g}$ de selenometionina em indivíduos com deficiência de selênio durante 12 meses, observaram redução significativa de anticorpo TPOAb $\left(1^{\circ}\right.$ trimestre $=5,6 \% ; 2^{\circ}$ trimestre $=9,9 \%$; e nos últimos 6 meses $=$ $8 \%$ ), sendo que o grupo não suplementado, no último semestre, apresentou aumento de $4,8 \%$, porém sem mudanças significativas nos hormônios tireoidianos (quadro 2). Farias et al..$^{24}$ encontraram resultados semelhantes ao utilizarem a mesma suplementação, observando ainda melhoras na vascularização tireoidiana e sem incremento dos marcadores de inflamação. 
Pirola et al., ${ }^{23}$ ao suplementarem indivíduos com tireoidite de Hashimoto com $83 \mu \mathrm{g}$ de selenometionina, durante quatro meses, observaram redução significativa de anticorpos e de TSH ( p <0.0001) em 31\% da amostra, sendo a suplementação capaz de restaurar o estado eutireoidiano em $17,2 \%$ dos indivíduos. Nordio e Pajalich ${ }^{22}$ e Nordio e Basciani ${ }^{21}$ encontraram resultados semelhantes ao associarem a suplementação de $83 \mu \mathrm{g}$ de selenometionina a $600 \mathrm{mg}$ de myo-inositol, sendo que o último observou ainda melhora na qualidade de vida dos indivíduos, estando de acordo com Uysal e Ayhan. ${ }^{36}$ Os referidos autores realizaram estudo transversal observando uma relação inversa entre os níveis séricos de anticorpos e qualidade de vida $(\mathrm{p}<0,001)$, avaliada através de questionários. A suplementação de selênio é potencializada quando associada ao myo-inositol, sendo esse um precursor do inositol trifosfato, cuja função é regular a atividade de alguns hormônios, dentre os quais, o TSH. ${ }^{21,22}$

Dois estudos realizaram a suplementação com selenito de sódio, encontrando resultados divergentes. Nocamulli et al., ${ }^{25}$ ao utilizarem uma dose de $80 \mu \mathrm{g}$, observaram redução significativa de TPOAb $(\mathrm{p}<0,0001)$ após 12 meses de intervenção, porém sem mudanças no perfil hormonal. Esse estudo não analisou as quantidades séricas de selênio na amostra, podendo ter influenciado nos resultados. Por outro lado, Eskes et al., ${ }^{28}$ ao suplementarem indivíduos que apresentavam deficiência leve de selênio com $200 \mu \mathrm{g}$ durante seis meses, não observaram mudanças significativas de TPOAb ou hormônios tireoidianos. A deficiência de selênio apresentada pela amostra desse estudo, foi menor em relação aos estudos que encontraram resultados positivos com a suplementação.

Cabe discutir que os estudos não apresentam padronização quanto à fórmula a ser utilizada (selenometionina ou selenito de sódio), o que é um fator relevante, uma vez que seguem vias metabólicas diferentes. Após saturação, a selenometionina é capaz de interferir nos níveis séricos de selênio, por meio de sua incorporação não regulada em proteínas contendo metionina, enquanto que o selenito de sódio não será mais utilizado eficientemente para a biossíntese de selenocisteína. ${ }^{28}$ A biodisponibilidade do selenito de sódio representa dois terços da absorção da selenometionina, sugerindo, assim, maior eficácia da suplementação desta quando comparada ao selenito de sódio. ${ }^{37}$

Interessante notar também que a quantidade de selênio no solo constitui outro fator que pode estar associado ao risco em desenvolver a tireoidite de Hashimoto. Wu et al., ${ }^{38}$ analisando essas variáveis em indivíduos oriundos de duas regiões - Ningshan (baixos níveis de selênio no solo) e Ziyang (níveis adequados de selênio no solo) -, constataram maior prevalência e risco maior (69\%) em desenvolver qualquer distúrbio tireoidiano nos indivíduos residentes em regiões deficientes em selênio. Nesse estudo, o consumo de carne foi fator protetor contra o desenvolvimento de hipotireoidismo e o consumo de chá verde enriquecido com esse mineral (hábito da região) esteve associado a um menor risco de desenvolver hipotireoidismo (38\%) e hipotireoidismo subclínico (45\%). 
Esposito et al. ${ }^{26}$ suplementaram indivíduos residentes do Sul da Itália, região que apresenta deficiência leve de selênio no solo, com $166 \mu \mathrm{g}$ de selenometionina, durante seis meses, não encontrando redução significativa de anticorpos. Houve, no entanto, mudanças significativas nos hormônios tireoidianos T3 $(\mathrm{p}<0,04)$ e T4 $(\mathrm{p}<0,03)$, sugerindo maior atividade de DIO induzida pela suplementação. Esse artigo não analisou as quantidades séricas de selênio na amostra, o que pode ter influenciado nos resultados. Outrossim, a dose utilizada foi menor em relação aos estudos que encontraram efeitos benéficos com a suplementação de selenometionina, podendo esta não ter sido suficiente para a redução de anticorpos.

Por fim, estudos realizados com indivíduos que não apresentavam deficiência de selênio não encontraram benefícios com a suplementação tanto de selenometionina quanto de selenito de sódio. Isso pode ter ocorrido uma vez que a absorção intratireoidiana deste mineral é limitada e uma administração adicional não traria benefícios na redução de anticorpos. ${ }^{27,28}$

Dessa forma, as evidências científicas a respeito da suplementação de selênio no hipotireoidismo de Hashimoto são controversas, embora promissoras em indivíduos que apresentam a deficiência desse mineral. Portanto, a padronização metodológica é fundamental, a fim de estabelecer a dose ótima e o tempo de suplementação, bem como a fórmula a ser utilizada. Destaca-se, ainda, que os estudos não investigam, necessariamente, a deficiência desse mineral, mas apenas o efeito da suplementação sobre os níveis de anticorpos.

\section{Conclusão}

A deficiência de vitamina $\mathrm{D}$ foi mais prevalente em indivíduos com a tireoidite de Hashimoto e associada a maior expressão de células Thl, maior produção de linfócitos B e, consequentemente, maior produção de anticorpos. Por outro lado, na deficiência de selênio pode ocorrer menor atividade de GPX, TR e DIO, e produção de T3 e eliminação de $\mathrm{H}_{2} \mathrm{O}_{2}$ ineficientes, contribuindo, assim, para a iniciação do processo oxidativo, fibrose e reparação prejudicada de tecidos tireoidianos. Entretanto, mais estudos são necessários para esclarecer se a redução dos níveis séricos de vitamina D é um fator causal ou uma consequência do hipotireoidismo de Hashimoto.

Quanto à suplementação, observou-se que esta parece ser eficaz para a redução de anticorpos em pessoas que apresentam a doença. Porém, destacam-se a escassez de estudos experimentais, a falta de padronização metodológica e que apenas os indivíduos com deficiência de selênio foram beneficiados, uma vez que a absorção intratireoidiana desse mineral é limitada e uma administração adicional não traria benefícios. Todavia, não há evidências científicas suficientes que apoiem o uso de suplementos como estratégia terapêutica na tireoidite de Hashimoto. 


\section{Colaboradores}

Vilela LRR participou da concepção do projeto, pesquisa bibliográfica e da redação do artigo; Fernandes DC participou da pesquisa bibliográfica, redação e revisão final do artigo.

Conflito de interesses: Os autores declaram não haver conflito de interesse.

\section{Referências}

1. Lima LC, Reis NT. Interpretação de exames laboratoriais aplicados à nutrição clínica. In: Pereira AS, Coelho SC, Calixto-Lima L, Siqueira RA. Doença da Tireoide: Hiper e Hipotireoidismo. Rio de Janeiro: Rubio; 2012. p.175-187.

2. Tamer G, Arik S, Tamer I, Coksert D. Relative Vitamin D insufficiency in Hashimoto's Thyroiditis. Thyroid. 2011; 21(8):891-896.

3. Eugenia P, Dumitrache C, Andra B, Maria O, Irina P, Nicoleta D, et al. Vitamin D and thyroid autoimmunity. ARS Medica Tomitana. 2015; 3(21):157-162.

4. Bozkurt CN, Karbek B, Ucan B, Sahin B, Cakal E, Ozbek M, et al. The association between severity of vitamin d deficiency and hashimoto's thyroiditis. Endocrine Practice. 2013; 9(3):1-6.

5. Giovinazzo S, Vicchio TM, Certo R, Alivrandi A, Palmiere O, CampennI A, et al. Vitamin D receptor gene polymorphisms/haplotypes and serum 25(OH)D3 levels in Hashimoto's thyroiditis. Endocrine. 2016; 55(2):599-606.

6. Drutel A, Archambeaud F, Caront P. Selenium and the thyroid gland: more good news for clinicians. Clin Endocrinol (Oxf). 2013; 78(2):155-164.

7. Wiersinga WM. Clinical relevance of environmental factors in the athogenesis of autoimmune Thyroid Disease. Endocrinol Metab (Seoul). 2016; 31(2):213-222.

8. Ayaz T, Sahin SB, Sahin OZ, Cure MC, Sumer F, Llkkilic K. Serum macrophage migration inhibitory factor levels in Hashimoto's thyroiditis: a case control study. Thyroid Res. 2014; 7(11). Disponível em: https://www.ncbi.nlm.nih.gov/pmc/articles/PMC4265349/pdf/13044_2014_Article_11.pdf

9. Moher D, Liberati A, Tetzlaff J, Altman DG. Preferred reporting Items for systematic reviews and meta-analyses: the PRISMA statement. Plos Med. 2009; 6(7):e1000097.

10. Maciejewski A, Wójcicka M, Roszak M, Losy J, Lącka K. Assessment of Vitamin D levelin autoimmune Thyroiditis patientsand a control group in the polish population. Adv Clin Exp Med. 2015; 24(5):801806.

11. Ma J, Wu D, Li C, Fan C, Chao N, Liu J, et al. Lower Serum 25-Hydroxyvitamin D level is associated with 3 types of autoimmune Thyroid Diseases. Medicine (Baltimore). 2015; 94(39):e1639.

12. Mansournia N, Mansournia MA, Saeedi S, Dehghan J. The association between serum 25OHD levels and hypothyroid Hashimoto's thyroiditis. J Endocrinol Invest. 2014; 37(1):473-476.

13. Shin DY, Kim KJ, Kim D, Hwang S, Lee EJ. Low Serum Vitamin D is associated with anti-thyroid peroxidase antibody in autoimmune Thyroiditis. Yonsei Med J. 2014; 55(2):476-481. 
14. Unal AD, Tarcin O, Parildar H, Cigerli O, Eroglu H, Demirag NG. Vitamin D deficiency is related to thyroid antibodies in autoimmune thyroiditis. Cent Eur J Immunol. 2014; 39(4):493-497.

15. Guleryuz B, Akin, F, Ata MT, Dalyanoglu MM, Turgut S. Vitamin-D Receptor (VDR) Gene Polymorphisms (TaqI, FokI) in Turkish patients with Hashimoto's Thyroiditis: relationship to the levels of Vit-D and Cytokines. Endocr Metab Immune Disorders. 2016; 16(2):131-139.

16. Kim D. Low vitamin D status is associated with Hypothyroid Hashimoto's Thyroiditis. Hormones. 2016; 15(3):385-393.

17. Wang J, Lv S, Chen G, Gao C, He J, Zhong H, et al. Meta-analysis of the association between Vitamin D and autoimmune Thyroid Disease. Nutrients. 2015; 7(4):2485-2498.

18. Mazokopakis EE, Papadomanolaki MG, Tsekouras KC, Evangelopoulos AD, Kotsiris DA, Tzortzinis AA. Is vitamin D related to pathogenesis and treatment of Hashimoto's thyroiditis? Hell J Nuc Med. 2015; 18(3):222-227.

19. Chaudhary S, Dutta D, Kumar M, Saha S, Mondal SA, Kumar A, et al. Vitamin D supplementation reduces thyroid peroxidase antibody levels in patients with autoimmune thyroid disease: an openlabeled randomized controlled trial. Indian J Endocrinol Metab. 2016; 20(3):391-398.

20. Mazokopakis EE, Papadakis JÁ, Papadomanolaki MG, Batistakis AG, Giannakopoulos TG, Protopapadakis EE, et al. Effects of 12 months treatment with L-Selenomethionine on serum antiTPO levels in patients with Hashimoto's Thyroiditis. Thyroid. 2007; 17(7):609-612.

21. Nordio M, Basciani S. Treatment with myo-inositol and selenium ensures euthyroidism in patients with autoimmune Thyroiditis. Int J Endocrinol. 2017; 2017. Disponível em: https://www.ncbi.nlm. nih.gov/pmc/articles/PMC5331475/pdf/IJE2017-2549491.pdf

22. Nordio M, Pajalich R. Combined treatment with Myo-Inositol and Selenium ensures Euthyroidism in subclinical Hypothyroidism patients with autoimmune Thyroiditis. Journal of Thyroid Research 2013; (2013). Disponível em: https://www.hindawi.com/journals/jtr/2013/424163/

23. Pirola I, Gandossi E, Agosti B, Delbarba A, Cappelli C. Selenium supplementation could restore euthyroidismin subclinical hypothyroid patients with autoimune thyroiditis. Endokrynol Pol. 2016; 67(6):567-571.

24. Farias CR, Cardoso BR, Oliveira GMB, Guazzelli ICM, Catarino RM, Chammas MC, et al. A randomized-controlled, double-blind study of the impact of selenium supplementation on thyroid autoimmunity and inflammation with focus on the GPx1 genotypes. J Endocrinol Invest. 2015; 38(10):1065-1074.

25. Nacamulli D, Mian C, Petricca D, Lazzarotto F, Barollot S, Pozza D, et al. Influence of physiological dietary selenium supplementation on the natural course of autoimmune thyroiditis. Clin Endocrinol (Oxf). 2010; 73(4):535-539.

26. Esposito D, Rotondi M, Accardo G, Vallones G, Conzo G, Docimo G, et al. Influence of hortterm selenium supplementation on the natural course of Hashimoto's thyroiditis: clinical results of a blinded placebo-controlled randomized prospective trial. J Endocrinol Invest. 2016; 40(1):83-89.

27. Anastasilakis AD, Toulis KA, Nisianakis P, Goulis DG, Kampas L, Valeri RM, et al. Selenomethionine treatment in patients with autoimmune thyroiditis: a prospective, quasi-randomised trial. Int J Clin Pract. 2012; 66(4):378-383. 
28. Eskes AS, Endert E, Fliers E, Birnie E, Hollenbach B, Schomburg L, et al. Selenite supplementation in euthyroid subjects with thyroid peroxidase antibodies. Clin Endocrinol (Oxf). 2014; 80(3):444-451.

29. Rogerio MM, Fock RA, Borelli P. Nutrição e Sistema Imune. In: Cozzolino SMF, Cominetti C, organizadores. Bases biquímicas e fisiológicas da nutrição nas diferentes fases da vida, na saúde e na doença. São Paulo: Manole; 2013. p. 1086-1121.

30. Holick MF, Binkley NC, Bischoff-Ferrari HA, Gordon CM, Hanley DA, Heaney RP, et al. Evaluation, treatment, and prevention of vitamin $\mathrm{D}$ deficiency: an endocrine society clinical practice guideline. J Clin Endocrinol Metab. 2011; 96(7):1911-1930.

31. Djurovic J, Stojkovic O, Ozdemir O, Silan F, Akurut C, Todorovic J, et al. Association between FokI, ApaI and TaqI RFLP polymorphisms in VDR gene and Hashimoto's thyroiditis: preliminary data from female patients in Serbia. Int J Immunogenet. 2015; 42(3):190-194.

32. Feng M, Li H, Chen SF, Li WF, Zhang FB. Polymorphisms in the vitamin D receptor gene and risk of autoimmune thyroid diseases: a meta-analysis. Endocrine 2013; 43(2):318-326.

33. Kohrle J, Jakob F, Contempre B, Dumont JE. Selenium, the thyroid, and the endocrine system. Endocr Rev. 2005; 26(7):944-984.

34. Combs GF, Midthune DN, Patterson KY, Canfield WK, Hill AD, Levander OA, et al. Effects of selenomethionine supplementation on selenium status and thyroid hormone concentrations in healthy adults. Am J Clin Nutr. 2009; 89(6):1808-1814.

35. Schmutzler C, Mentrup B, Schomburg L, Hoang-vu C, Herzog V, Kohrle J. Selenoproteins of the thyroid gland: expression, localization and possiblefunction of glutathione peroxidase 3. Biol Chem. 2007; 388(10):1053-1059.

36. Uysal HB, Ayhan M. Autoimmunity affects health-related quality of life in patients with Hashimoto's thyroiditis. Kaohsiung J Med Sci. 2016; 32(8):427-433.

37. Burk RF, Norsworthy BK, Hill KE, Motley AK, Byrne DW. Effects of chemical form of Selenium on plasma biomarkers in a high-dose human supplementation trial. Cancer Epidemiol Biomarkers Prev. 2006; 15(4):804-810.

38. Wu Q, Rayman MP, Lv H, Schomburg L, Cui B, Gao C, et al. Low population selenium status is associated with increased prevalence of thyroid disease. J Clin Endocrinol Metab. 2015; 100(11):4037-4047.

Recebido: 22 de setembro, 2017

Revisado: 11 de março, 2018

Aceito: 20 de março, 2018 